\title{
PORTUGAL E BRASIL: ENTRE VIOLAS E PRÁTICAS SOCIOCULTURAIS NO CONTEXTO TRANSATLÂNTICO
}

\section{PORTUGAL AND COLONIAL BRAZIL: BETWEEN VIOLAS AND SOCIO-CULTURAL PRACTICES IN THE TRANSATLANTIC CONTEXT}

\author{
José Jarbas Ruas \\ Universidade Federal do Tocantins \\ jiruas@uft.edu.br
}

\section{Resumo}

presente artigo tem como objetivo ressaltar aspectos pertinentes às práticas socioculturais elementares a espacialidade e temporalidade entre Brasil e Portugal. Prestígio e depreciação são personagens importantes que protagonizam a história do instrumento. As práticas musicais, com estreitamento ao cotidiano musical vivenciado pela viola em ambas as localidades, são estudadas aqui com o objetivo de observar a manutenção de hábitos entre tais territorialidades que nos permitem propor à desconstrução das limitações fronteiriças transatlânticas dadas as transplantações de hábitos, costumes, valores e visões de mundo entre as partes.

Palavras-chave: Viola; Brasil Colônia; Portugal; Práticas socioculturais.

\section{Abstract}

This article aims to highlight relevant aspects of the basic cultural practices spatiality and temporality between Brazil and Portugal. Prestige and depreciation are important characters who star in the history of the instrument. Musical practices, narrowing the musical daily experienced by the viola in both locations are studied here in order to observe the maintenance habits among such territoriality that allow us to propose the deconstruction of transatlantic border limitations given transplants of habits, customs, values and world views between the parties.

Keywords: Viola; Brazil colony; Portugal; Socio-cultural pratices. 
Viola: Instrumento músico de cordas. Tem corpo côncavo, costas, tampo, braço,

Espelho, cavalete para prender as cordas, e pestana para as dividir, e para as por em proporção igual, tem onze trastos, para se dividirem as vozes,

e para se formarem as consonâncias. Tem cinco cordas, a saber, a primeira, a segunda, e corda prima, a contra-prima, e o bordão.

(Raphael Bluteau)

\section{Introdução}

A viola, em suas diferentes formas, afirma-se como um instrumento atuante na música lúdica e sentimental de caráter festivo, alegre, viva ou acentuadamente lírica no Brasil e em Portugal. Trata-se de um instrumento de caráter popular, presente nos folguedos rurais e de rua, a serviço dos amores, devaneios, diversões e folias (OLIVEIRA, 1966; BUDASZ, 200 1; VILELA, 20 13).

instrumento mostra-se muito corrente na história da sociedade portuguesa até o seu provável declínio ao final do século XVIII. Como termômetro a essa afirmativa, buscamos respaldo na fala de Paixão Ribeiro (1789) quando diz que "a viola tem perdido muito da sua estimação, por não haver hoje quase pessoa alguma que não se jacte de a tocar" (1789, p.2). A progressiva decadência, beirando o desaparecimento em algumas regiões de Portugal, se dá a partir da chegada do violão de seis cordas. Nestas localidades, o instrumento é substituido, porém, continua a ser chamado de viola (OLIVEIRA, 1966).

Em sua trajetória, a viola é considerada como o instrumento fundamental $e$ importante em Lisboa para o acompanhamento de modinhas, lundus e o próprio fado oitocentista. A atuação do instrumento não se encerra apenas ao contexto popular. Os repertórios publicados durante os séculos XVI e XVII, para a viola de cinco ordens, são parte importante desta história, embora nesta comunicação não estejam no cerne de nossa exposição. Portugal, Espanha, França e Itália, com suas respectivas violas dedilhadas, dispõem de edições documentadas que a imprensa tornou possivel.

O estudo organológico de Oliveira (1966) apresenta uma ampla trajetória a respeito da viola em suas diferentes construções e práticas musicais ao longo do tempo. Sobre a viola de cinco ordens Budasz (200 1 ) estabelece relações sobre o repertório praticado ao instrumento no contexto Brasil e Portugal. 
Os vários modelos de viola, com características estruturais particulares, dadas as localidades regionais em Portugal e Brasil, mostram o quão plural esse instrumento se fez nas práticas socioculturais lusófonas.

\section{Vias socioculturais transatlânticas entre Portugal e Brasil}

Entender a ocupação portuguesa, seus valores socioculturais, e as transformações aplicadas à recém-descoberta Terra de Santa Cruz nos remete a considerar aspectos que remontam as próprias transformações as quais a Metrópole europeia também passava. Observar tais elementos, que viriam a ser transplantados posteriormente ao Brasil, coloca-nos na direção de suplantar as limitações geográficas do trânsito transatlântico entre Colônia e Metrópole.

Em 1500, Portugal descortinava a progressão marítima por meio de rotas no Atlântico e da costa da África garantindo-lhe a formulação de planos estratégicos. Entretanto, a sociedade portuguesa da segunda metade de Quatrocentos já passava por profundas transformações culturais. Inicia-se uma nova mentalidade diante das mudanças nas estruturas sociais. Surgem os primeiros grupos que passam a repartir o acelerado crescimento produtivo de uma era pré-capitalista.

Para essa sociedade, o mar torna-se um elemento de conhecimento responsável por uma formação de consciência social. $\bigcirc$ Portugal quinhentista vivenciava a chegada de dois novos paradigmas - o árabe e o mediterrâneo - em detrimento do enfraquecimento dos paradigmas que formularam a medievalidade - aristotélico, euclidiano, ptolomaico e boeciano. Para Almeida (2000),

O século XV português foi tributário de todas estas fontes, pois conheceu intensa circulação das suas ideias, mas deve ter-se presente que este século é um tempo muito especial na consolidação da comunidade portuguesa, quer do ponto de vista da vida material, quer nos aspectos das formações mentais e das matrizes culturais que viriam a identificar a cultura então em gestação. Sem dúvida o aparecimento da tipografia veio acelerar de múltiplas 
maneiras essa circulação, irritantemente restritiva, no tempo em que o suporte da informação era manuscrito. $\bigcirc$ uso crescente das linguagens romance veio alargar, por seu lado, o universo da recepção, acentuando a implantação das ideias científicas na tessitura social, e pondo o conhecimento científico ao serviço dos grupos sociais dominantes. (p.81)

A descoberta do Novo Mundo, ou seja, das terras além-mar, possivelmente implicaram num grande esforço de compreensão de tal fenômeno para os europeus. A reorganização do espaço geográfico envolveu gradual, porém, profundas mudanças na mentalidade europeia.

A ocupação do solo no Portugal quinhentista segundo Ruy de Pina figurava entre "aldeias" e "desertos" se comparados a Lisboa. A concentração populacional se dava em cidades, vilas e aldeias cercadas por muralhas e ruas tortuosas, no topo de um monte (COSTA LOBO, 1904, p.96; p.100). Na primeira metade do século XV as populações rurais estavam reunidas a volta de pequenos centros autossuficientes. Como a economia desses territórios era predominante agrícola, se isso não acarreta a uma proposição anacrônica, "o núcleo urbano dos municípios funcionava apenas como centro administrativo da área rural" (TINHORÃO, 2010, p.33).

Essa característica naturalmente fora transplantada pelos portugueses ao Brasil. Segundo Tinhorão,

as vilas e cidades dos dois primeiros séculos de colonização, não tendo como beneficiar-se da riqueza produzida à sua volta pela falta de um mercado interno [...] abrigavam uma população permanentemente reduzida e pobre, cuja sobrevivencia dependia de pequenas lavouras de subsistência, o que constituía mais uma forma de subordinar o meio urbano ao modo de vida rural (2010, p.35).

Esse modelo de adensamento populacional reduzia a capacidade de expansão territorial, mas conduzia ao aprofundamento das características locais. A manutenção desse modelo de ocupação talvez possa respaldar a hipótese da diversidade de formas de violas características das regiões geográficas de Portugal.

\section{3}




\section{Para Tinhorão (2010)}

A marca cultural de tais comunidades, isoladas nesse panorama de "aldeias e desertos" só podia ser a da valorização da identidade regional, através do reconhecimento geral de uma série de traços comuns, que dissolviam 0 individuo nas manifestações de coletividade. E isso queria dizer que, quando tal gente rural se divertia em suas pequenas vilas e povoados, suas danças e cantos constituíam sempre reuniões da comunidade ao ar livre, com rodas $e$ ares evoluindo nos terreiros ao som de instrumentos feitos para animar o ritmo e dominar o alarido (2010, p.17)

O século XV aponta para um novo comportamento: a individualidade. Seria este o elemento que fundamentaria as concepções de identidade do que futuramente viria a ser o sujeito do lluminismo. Os núcleos urbanos passam a receber os trabalhadores rurais oriundos do exodo provocado pela redução da agricultura de subsistência diante da mercantilização da exportação. Serão estes os agentes que vão aderir, não somente as grandes navegações, mas tornar-se-ão os eventuais vadios, espertos e zombadores urbanos.

Surge um novo elemento: a singularidade do canto a solo com acompanhamento individual ao som da viola. Uma prática que envolve o intercâmbio entre a tradição rural e urbana; uma ação que marca a coexistência de manifestações elementares entre a aristocracia, a burguesia e a forma de diversão popular derivada da tradição rural. Tal prática se tornaria típicas nas cidades. Surge nesse momento uma música dirigida às distrações urbanas. (TINHORÃO, 2010)

Pelo que se conhecem, já nos princípios do terceiro quartel do século XV, os prevaricadores da moral e dos bons costumes, acompanhados de suas violas promoviam os maiores estragos no reino, de Norte a Sul. A viola era o apelo à amada para viverem as aventuras do amor. Data de 1459, o documento enviado pelos Procuradores de Ponte de Lima à Corte de Lisboa, mencionando os "males causados pela viola ao reino". O documento solicitava ao rei a proibição de serenatas públicas, dado a desinquietação provocada em todo o reino. Ao tangerem seus instrumentos, os violeiros conseguiam persuadir as senhoritas a abrirem as portas de suas casas por meio de suas canções entoadas à noite serenata -, fato este considerado uma transgressão dos valores morais.

\section{4}


Oliveira descreve algumas ações destes grupos formados por violeiros.

Ajuntam-se de dez e dez homens e levam uma viola e três e quatro estavam tangendo e os outros então escalam as casas e roubam os homens de suas fazendas. E outros que tem más mulheres e más filhas criadas, como ouvem tanger a viola vêm-lhes desfechar as portas e dormem com elas. E quando se despedem levam alguma coisa (1966, p. 46).

D. Afonso V (|432-1481) lança o decreto para que todos os prevaricadores, surpreendidos em flagrante, que fossem presos perderiam a viola, vestidos e armas com que fossem apanhados, revertendo estas para o respectivo alcaide e o restante para aqueles que os prendessem. Tais "medidas repressivas foram afrouxando com o tempo ou porque os maus hábitos podem sempre mais que as boas leis", mas, também porque, "a viola continuou a ser o grande atrativo e tentação popular, pondo de lado a maioria dos restantes instrumentos típicos." (FERREIRA, 1990, p. 14)

A encenação do cotidiano na dramaturgia portuguesa quinhentista através de Gil Vicente ${ }^{1}$ descreve os temas da uma nova vida que nasce em Portugal e retrata uma música que surge no povo, acompanhada pela viola.

I Gil Vicente (1465-1536) é considerado o primeiro grande dramaturgo e poeta português de renome. Parece ter desempenhado as tarefas de músico, ator e encenador. Sua obra é considerada um reflexo que ilustra a transição entre a ldade Média e a Renascença, incorporando elementos da cultura popular portuguesa em suas obras. Segue a relação que compõe a obra do autor com o seu respectivo ano: Auto do vaqueiro ou Auto da visitação (1502); Auto Pastoril Castelhano (1502); Auto dos Reis Magos (1503); Auto de São Martinho (1504); Quem tem farelos? (1505); Auto da Alma (1508); Auto da Índia (1509); Auto da Fé ( 5 | 10); $\bigcirc$ velho da horta (15 | 2); Exortação da Guerra ( 5 | 3); Comédia do viúvo (15|4); Auto da Fama (1516); Auto da barca do inferno (1517); Auto da barca do purgatório (1518); Auto da barca da glória (1519); Cortes de Júpiter (1521); Comédia de Rubena (1521); Farsa de Inês Pereira (1523); Auto pastoril português (1523); Frágua de amor (1524); Farsa do juiz da Beira (1525); Farsa do templo de Apolo (1526); Auto da nau de amores (1527); Auto da História de Deus (1527); Tragicomédia pastoril da Serra da Estrela (1527); Farsa dos almocreves (1527); Auto da feira (1528); Farsa do clérigo da Beira (1529); Auto do triunfo do Inverno (1529); Auto da Lusitânia, intercalado com o entremez Todo-o-Mundo e Ninguém ( 1532); Auto de Amadis de Gaula (1533); Romagem dos Agravados (1533); Auto da Cananea (1534); Auto de Mofina Mendes (1534); Floresta de Enganos (1536). Em negrito estão as obras que fazem menção à viola segundo Ferreira (1990).

\section{5}


As vias socioculturais transatlânticas pautadas nos costumes, valores e práticas sociais entre Metrópole e Colônia podem ser vistas como complementares e contínuas se desconstruirmos a limitação territorial de fronteiras entre as partes. $\bigcirc$ processo de individualização do homem urbano, pautado no novo projeto econômico das navegações começava a produzir seus efeitos no plano cultural. Ao substituir sua vida simples pelo clima competitivo das cidades, o tom alegre expresso das festividades rurais dá lugar aos versos que expressam as dificuldades de uma nova vida, agora urbana.

Quando a Metrópole dá início ao processo de colonização, transplantando parte de sua população para a Colônia,

os duzentos primeiros anos de colonização brasileira nada mais representaram do que uma reprodução da realidade da vida da metrópole, não seria hoje possivel compreender o cotidiano das cidades no Brasil até ao século XVIII, o próprio processo de urbanização em Portugal (TINHORÃO, 2010, p. 16)

\section{Entre monarcas portugueses, por que não música e viola?!}

$\bigcirc$ gosto pela música e pela viola, entre a nobreza e o povo, subsistiu por décadas entre os portugueses. Fernão Lopes, o primeiro cronista português, ao descrever fatos sobre a monarquia de D. Pedro I, entre os anos de 1357 e 1367 menciona o hábito de tanger e cantar à viola como parte do ofício do escudeiro.

D. João III (1502-1557) conhecido como o "Piedoso" ou o "Colonizador" teve em sua corte um violeiro privativo, Diogo Dias, nomeado para tal função por meio de alvará real datado de 24 de maio de 1551. O monarca teve ainda obras de outros músicos dedicados a ele. Para tanto destacamos a Declaración de Instrumentos Musicales (Ossuna, 1549) de Juan Bermudo (1510-1565) e El maestro2 (Valencia, 1536) de Luys Milan (1500-156 1).

2 "Dirigido al muy alto e muy poderoso y invictissimo príncipe Don Juhan; por lagracia de Dios rey de Portugal y de las islas" dedicatória do tratado de vihuela El Maestro ao príncipe D. João. 
Durante o reinado de D. Sebastião3 (1554-1578) temos a primeira menção à regulamentação das atividades dos violeiros através do Regimento dos Violeiros, publicado em 1572. A popularidade da viola entre os portugueses, mesmo diante de um número possivelmente exagerado, é registrada pelo fatídico encontro de 10 mil violas, abandonadas pelos portugueses na batalha. A campanha bélica portuguesa em Alcácer-Quibir trouxe a óbito D. Sebastião. Com sua morte em 1578 e de grande parte da nobreza nos campos de batalha, Portugal enfrenta uma grave perda de poder institucional no regime absoluto de monarquia hereditária promovendo um impasse ao funcionamento das instituições durante o breve reinado do Cardeal-Rei até 1580.

Durante os sessenta anos (1580-1640) de dominação espanhola sobre o território, alguns músicos portugueses ${ }^{4}$ optaram por se mudar e prestar serviços musicais a nobres. Reconquistando sua soberania agora liderados pela família de Bragança -, Portugal começa a criar novas alianças com os demais reinos europeus e assume uma postura que será comum aos monarcas que ocuparão o trono ao longo do século XVIII e XIX. A neutralidade e a diplomacia tornam-se as principais armas da coroa portuguesa para evitar embates que pudessem comprometer novamente suas fronteiras - continental e, principalmente, a marítima. Uma eventual guerra não deixaria livre de consequências os territórios ultramarinos.

Durante o século XVIII há uma crescente atividade e movimentação social para realização de concertos públicos e privados em Portugal. Segundo o autor a confirmação desses eventos permite destacar marcos como os "saraus e músicas das senhoras" na corte. Tais concertos

\footnotetext{
3 A D. Sebastião são atribuidos uma série de eventos conferidos ao campo diplomático de expansão, afirmação e domínio português na política do Atlântico Sul. "A abertura do percurso marítimo do Atlântico à livre iniciativa dos seus vassalos, o interesse por Angola, pela Mina, pelas thas e pelo Brasil, o incentivo à evangelização, agora confiada prioritariamente à Companhia de Jesus. É no seu tempo reconquistado o Rio de Janeiro e os franceses são afastados da Baía de Guanabara; continuam-se as relações com o Império Alemão, cujos comerciantes encaram o comércio com o Oriente por roła portuguesa em novos termos. Renovam-se as relações diplomáticas diretas com a Inglaterra, enquanto a corte portuguesa quereria aproximar as cortes de Lisboa e de Paris, propondo-se, para isso, o casamento de D. Sebastião com a filha de Catarina de Médicis. As relações de Portugal e da Santa Sé, no tempo do pontificado de Pio V, eram auspiciosas" (BARATA, 2000, p. 114)

4 Em 1640, aos serviços do duque de Medina das Torres, em Nápoles, Nicolao Doizi de Velasco publicou Nuevo Modo de Cifra difundindo o sistema de notação de acordes Alfabeto - devido à grande quantidade de músicos mediocres que geralmente aplicavam harmonias erradas ao executar passacalles e tonos.
}

\section{7}


tornam-se frequentes após a chegada da rainha D. Mariana da Áustria em 1708. São abundantes as referências a serenatas, bailes (jogos de cartas) particulares ou semi públicos em várias casas aristocráticas, sobretudo a partir de 1733, durante o período joanino (BRITO, 1989, p. 167).

Ao longo do século XVIII, um número significativo de estrangeiros habitou em Portugal. César de Saussure, um suíço que residiu em Portugal no ano de 1730, descreve aspectos da vida social portuguesa composta por uma burguesia mercantilista estrangeira. A guitarra, ou a viola - instrumento de corda dedilhada - mostrava-se ainda entre as principais formas de entretenimento dos portugueses para o acompanhamento de suas canções em suas atividades e manifestações públicas, como serenatas e saraus.

Não faço ideia daquilo em que os portugueses se recreiam ou divertem além da guitarra. Excetuando os que viajam, não creio que se entretenham a jogar. Não tem comédia, nem ópera nem concertos, exceto os de igreja. Creio que não sabem o que é um baile. Os ingleses, franceses e holandeses aqui estabelecidos como comerciantes organizaram um belo concerto composto por uma vintena de instrumentos e de oito a dez vozes, duas ou três das quais aformoseadas por meio de uma cruel operação. A maior parte destes músicos são italianos. Realiza-se estes concerto uma vez a cada semana numa grande sala excelentemente iluminada. Os subscritores não pagam nada pelo espetáculo e os que não são ou são estrangeiros pagam uma pequena importância. Durante o inverno alternam os concertos com bailes. Pelo baile paga-se o dobro do que custa o concerto. Servem chocolate ou chá, vinhos finos, doçaria e coisas semelhantes. Habitualmente, tanto nos concertos como nos bailes há numerosa e brilhante companhia dos dois sexos e de nacionalidades várias - ingleses, franceses, holandeses e outros. Portugueses encontram-se poucos ali e portuguesas ainda menos. Não obstante ali estive com duas ou três senhoras cujos maridos foram embaixadores em França, Inglaterra e outros países e que tendo-os acompanhado se humanizaram um tanto. Contígua à sala do baile ou do concerto há duas ou mais câmaras onde se servem refrescos e onde muitas vezes os homens jogam forte. É este o único divertimento público que existe. (BRITO, 1989, p. 168)

\section{8}




\section{Allgemeine Musikalische Zeitung: crônicas sobre a vida musical portuguesa}

Alguns aspectos da vida musical portuguesa do final do século XVIII e parte do XIX são retratados pelas crônicas musicais dirigidas ao periódico musical alemão Allgemeine Musikalische Zeitung. Reservar-nos - emos aqui a descrever duas das crônicas que fazem menção a viola. Dentre as primeiras crônicas encaminhadas ao periódico talvez seja esta a que melhor possa nos oferecer informações sobre a diversidade musical portuguesa neste período. Nela encontramos menção a gêneros musicais nos mais diversos segmentos sociais lisboetas. $\bigcirc$ cronista, constantemente, busca estabelecer relações entre a música praticada em Portugal com outros pontos da Europa.

Nesta crônica são abordadas as práticas musicais de três grupos sociais distintos, ressaltando a pluralidade e diversidade musical portuguesa. Logo, veremos a música praticada nos setores urbanos entre a nobreza e as classes populares, bem como nas áreas rurais.

primeiro gênero musical mencionado pelo cronista é a ópera seria. Cênero apreciado pela realeza portuguesa ao longo do século XVIII e XIX mantivera-se vivo e aquecido, não só em Portugal, como em boa parte da Europa. As empresas de espetáculos privilegiavam normalmente as montagens italianas. $\bigcirc$ cronista também destaca a preferência dada pelos compositores portugueses à língua italiana em vez da portuguesa em suas obras.

Já a ópera cômica e a opereta, com caráter mais popular, "fazem decerto mais sucesso e atraem público mais numeroso, embora não mais respeitável" (BRITO; CRANMER, 1989, p.34). Esses gêneros musicais, embora escritos em língua portuguesa, buscava a pronuncia mais próxima ao italiano.

Direcionando-se ao segmento rural da sociedade, o autor da crônica menciona que "mesmo nas aldeias é frequente encontrar pessoas de ambos os sexos capazes de improvisar uma segunda voz correta e agradável" e assim, descreve uma prática musical com melodias que não diferem muito da ldade Média. Trata-se de uma espécie de recitativo, em canto declamatório, "bastante a tempo e com acompanhamento geralmente em arpejos, para o qual improvisam a letra, ritmada e com rima, ou pelo menos com assonância". (BRITO; CRANMER, 1989, p.34) 
acompanhamento dessa prática musical, desenvolvida nas aldeias e regiões rurais - não se sabe ao certo que região-, dava-se com a viola de características igualmente representadas no tratado musical de Paixão Ribeiro dedicado ao instrumento, Nova Arte de Viola (1789). A Viola em questão tem como característica um total de doze cordas divididas em cinco ordens, das quais as três primeiras ordens, mais agudas, eram compostas por cordas duplas e as duas ordens restantes, mais graves, triplas.

Nesta crônica ainda há a descrição do acompanhamento deste canto declamatório "formado por acordes isolados, tocados da frente para trás (rasgado) e por um pequeno refrão no fim das estrofes". (BRITO; CRANMER, 1989, p.35)

Essa crônica trata ainda sobre uma prática nas festas populares portuguesas: a arte do cantar ao desafio. Nela, "os jovens colocavamse em fila e improvisavam cada um por sua vez, retomando a última frase do parceiro e acrescentando-lhes a continuação" (BRITO; CRANMER, 1989, p.35). Talvez, este cantar ao desafio seja a prática improvisativa em versos, acompanhada possivelmente à viola, que o viajante inglês A.P.D.C. ${ }^{5}$ descreve em seu diário quando esteve em Portugal. Talvez, seja possivel associá-lo ao relato de Adrien Balbi, quando reforça a tradição e prática de improvisação de versos com acompanhamento instrumental:

Pode-se dizer sem exageros que quase todo português, homem ou mulher, é um poeta lírico nato, pois em todo

\begin{abstract}
5 Nos saraus das classes cortesãs a música e a dança são os divertimentos usuais. A música é principalmente vocal, acompanhada pela viola, ou pelo piano, a harpa não está muito em uso. As canções executadas são italianas ou portuguesas, mas eles fariam melhor se se limitassem às suas modinhas que são realmente bonitas e nacionais, [...] a musica que os portugueses tocam na sua viola de corda de metal, consiste principalmente em valsas, landums, e nos acompanhamentos das suas modinhas. [...] Os landums são caracteristicamente mais portugueses do que qualquer outro tipo de música. A sua viola parece ser feita para este gênero de música. Para ser bem tocada é necessário que haja dois instrumentos, um dos quais toca apenas o motivo, ou tema, que é uma espécie de harpejo bonito e simples, enquanto o outro improvisa sobre este as melodias mais encantadoras. Nestas, dá-se rédea livre à imaginação mais musical e mais rica possivel, e são ocasionalmente acompanhadas pela voz, caso em que é habitual que as palavras sejam também improvisadas. Este gênero de musica é sempre de natureza amorosa e melancólica, a um tal grau, na verdade, que já o vi em muitas ocasiões provocar lágrimas naqueles ouvintes cujos corações estavam completamente enternecidos ou que encontravam nas palavras dos músicos qualquer coisa de análogo à sua própria situação. Numa modinha improvisada, no sentido mais estrito do termo, é costume que tanto as palavras como a música devem começar com um motivo, ao qual todo o resto deve referir-se.
\end{abstract}

\title{
210
}


Portugal, sobretudo na província do Minho e da Beira-Alta, não é raro encontrar simples camponeses que, sem jamais haver estudado, cantam, acompanham-se de sua guitarra, versos mais ou menos apaixonados, que surpreendem pela força da imaginação de quem os produz [...] (apud Fagerlade, 2008, p. 12)

As danças populares também são mencionadas. Segundo o cronista, as mais praticadas seriam a chula e a fofa, cujo gestual se assemelharia ao fandango espanhol e são executadas em dupla ou em grupo. (BRITO; CRANMER, 1989, p.35)

Retornando ao contexto urbano português, o cronista comenta sobre a música popular executada na cidade de Lisboa. Ele a descreve como canções de viela cujo teor temático faz "alusões a acontecimentos e a pessoas importantes, e são também bastante picantes" (BRITO; CRANMER, 1989, p.35). Cranmer e Brito sugerem que essas canções possam representar a matriz do fado. Segundo os autores esse gênero de canção se distingue claramente das modinhas de salão praticadas entre a classe "culta" portuguesa. (BRITO; CRANMER, 1989, p.27)

A efemeridade das modinhas é também representada nessa crônica. A curta validade remete-se ao consumo caracterizado pela constante renovação do repertório dessas canções para os saraus. "Quando já toda a gente as aprendeu e as canta, é difícil que alguém as deseje conservar" (BRITO; CRANMER, 1989, p.35).

A música de concerto também é mencionada. $\bigcirc$ cronista busca estabelecer uma relação entre a prática musical em Portugal e na Alemanha, expondo semelhanças e ressaltando as dificuldades quanto à prática do repertório pelos músicos.

Em Lisboa, como nas principais cidades alemãs, todo aquele que possui uma educação esmerada aprende e cultiva a música. Lá como cá, florescem concertos, óperas, missas, etc. Na música instrumental, os menos hábeis, lá como cá, gostam sobretudo de Boccherini e de Haydn, os mais hábeis de Haydn e de Mozart, só que na Alemanha, Boccherini tem menos procura e em Lisboa passa-se o mesmo com Mozart, sobretudo com suas sinfonias - o motivo, num caso e no outro, tem mais a ver com a habilidade dos músicos executantes do que com o gosto do público. (BRITO; CRANMER, 1989, p.35)

\section{1}


Outra crônica relevante sobre as práticas musicais portuguesas é a de 26 de junho de 1816. Nela o cronista faz menção à "música que é natural e própria desta nação" (BRITO; CRANMER, 1989, p.44), ou seja, a Modinha. Embora o gênero já fosse conhecido por alguns leitores devido à documentação feita através de narrativas de viagem ou pelos ensaios anteriores dirigidos ao jornal, sua crônica busca descrever a forma interpretativa e expressiva dessas canções:

Através do estilo muito próprio e frequentemente apaixonado de interpretação, conseguem ter bastante interesse, e, sobretudo, quando executadas por jovens do sexo oposto, um encanto indescritível. Infelizmente, é difícil exprimir por palavras esse encanto e descrevê-lo a quem não o tenha ouvido e visto (BRITO; CRANMER, 1989, p.44)

A crônica nos garante perceber a atuação feminina na música privada portuguesa. Algumas fontes iconográficas (imageml) além de retratar o apreço pela viola demonstra o instrumento sendo empunhado pelas senhoras ou senhoritas. $O$ tratado de Paixão Ribeiro (1789), publicado pela Real Universidade, na cidade de Coimbra, veio à luz mediante os incansáveis pedidos de mulheres que desejavam aprender a tocar o instrumento.

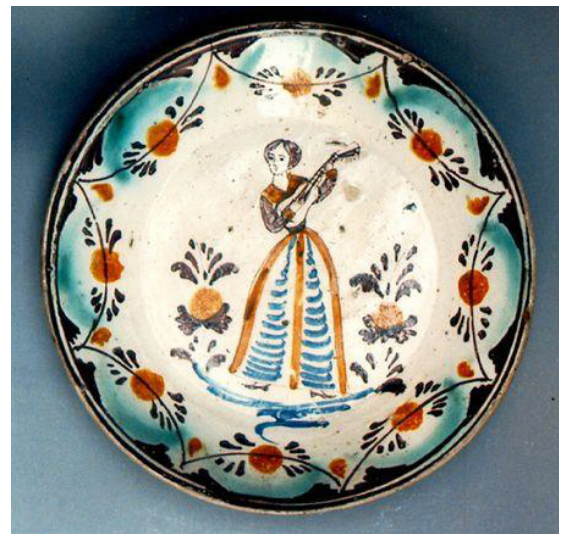

Figural - Mulher a tocar viola ${ }^{6}$

6 Museu: Museu Nacional Machado de Castro; N. de Inventário: 5697;C305; Supercategoria: Arte; Categoria: Cerâmica; Denominação: Prato; Autor: Desconhecido; Local de Execução: Portugal; Centro de Fabrico: Coimbra; Datação: 1850 d.C. - 1875 d.C; Matéria: Barro; Técnica: Faiança; Dimensões (cm): diâmetro: 30; Descrição: Forma circular e pintura a verde, amarelo e manganês (vinoso). Tem como motivo central uma figura feminina tocando viola. Aba decorada com grinal das esquematizadas. http://comjeitoearte.blogspot.com.br/201 1/1 1/o-fado-na-arte-ceramica.html

\section{2}


A respeito da forma de acompanhamento das modinhas, diz assim o cronista "o canto é habitualmente acompanhado por uma guitarra, e sabem ajustá-la tão intimamente ao canto que também ela aumenta e muito o agrado e encanto desta música, embora se limite a executar os acordes e arpejos mais simples". (BRITO; CRANMER, 1989, p.45)

A temática das Modinhas mantém-se restrita a um pequeno número de assuntos. Elas continuavam a ser escritas e publicadas a uma ou a duas vozes. Quando não havia uma segunda voz esta era acrescentada ou improvisada por um dos intérpretes. Segundo o cronista, a modinha estava difundida nos diferentes segmentos sociais da sociedade portuguesa, sendo cantada pelas camponesas no campo ou pela "gente comum" nas ruas da cidade à tardinha e à noite. As damas portuguesas também as apreciavam e "sabendo muito bem quanto elas próprias ficam encantadoras e gentis ao interpretá-las, cantamnas da melhor vontade". (BRITO; CRANMER, 1989, p.45)

As cantigas urbanas entoadas a solo, em inícios do século XVI, já revelam a preferência pelo acompanhamento ao som de viola. A paixão pelo instrumento ainda se mantinha viva por mais de dois séculos. A música produzida pela gente do povo das cidades, com intuito de atender ao lazer urbano possivelmente era acompanhada por diferentes tipos de violas dada a variedade de construtores. Essa música urbana que nasce no Portugal quinhentista é transplantada ao Brasil Colônia e traz consigo muitos elementos culturais da Metrópole. Ela é fruto da criação das camadas mais humildes oriundas de um novo homem das cidades.

\section{A viola e o Brasil}

A viola chega ao Brasil entre os primeiros instrumentos trazidos pelos jesuítas durante o processo de colonização. Taborda (2003) diz que $\mathrm{o}$ instrumento "tornou-se veículo preferencial para manifestação e o acompanhamento de gêneros musicais do tempo, marcando forte presença em diferentes manifestações culturais" (2003, p.15) no território nacional.

Segundo Holler (2010) as referências a violas nos textos jesuíticos sobre o Brasil são frequentes desde as últimas décadas do século 
$X V I$ até o final do século XVII7. Para o autor, não há dúvidas de que as violas mencionadas na documentação seja o instrumento dedilhado e não as violas da braccio ou da gamba. Segundo Castagna (1991),

as citações desse instrumento em Portugal e em suas colonias, durante os séculos XVI e XVII, são abundantes, sendo encontradas tanto na música profana quanto nas funções da igreja. A julgar pela documentação conhecida, pelo menos no século XVl, era o instrumento polifônico ou de harmonia mais difundido entre os povos ibéricos. No Brasil, pelo uso pouco frequente do cravo, foi o principal instrumento acompanhador e de harmonia na música profana até o século XVIII. É provável que fosse utilizado também em igrejas que não possuíam órgãos. (1991, vol.2, p.221, n. 173)

A monarquia portuguesa se imbuiu do fator moral que está ligado à ordem religiosa, na busca pela expansão e universalidade do cristianismo catolicista. Nesse contexto, podemos perceber um acordo de estreitamento nas relações entre Portugal e o Papa firmando o compromisso de levar a mensagem do evangelho aos limites da terra. Principalmente ao Novo Mundo, recém-descoberto (RUAS, 2013). A chegada do instrumento a Colônia é fruto do incentivo da monarquia portuguesa à evangelização gerenciada pela Companhia de Jesus 8 .

Segundo Taborda (2011), essa viola que chega ao Brasil é composta por três cordas duplas e uma prima simples. No século XVII, adquire mais uma ordem de corda. Na segunda metade do século XVIII, ainda outra. $\bigcirc$ instrumento transforma-se, agora com seis ordens de cordas duplas, que eventualmente se tornariam simples. Esta última alteração exigiria um aumento de tamanho do corpo do instrumento para compensar a perda de volume sonoro. "Tornou-se assim, viola grande. Ou violão" (TABORDA, 2011 , p. 47).

7 “Informações da província do Brasil de 1583", Padre Cristóvão de Gouveia. "Informação da missão do padre Cristóvão Gouveia às partes do Brasil", Padre Fernão Cardim de 1585. "Algumas coisas mais notáveis do Brasil", Padre Francisco Soares, 1590. "Relação da província do Brasil", padre Jácomo Monteiro, 1610. "Crônica da missão do Maranhão", padre João Felipe Bettendorf, 1698. (HOLLER, 2010)

8 Fundada por Inácio de Loyola a Companhia de Jesus foi criada oficialmente em 1540. Tinha como objetivo principal disseminar a palavra de Cristo entre os pagãos. Nove anos após a criação oficial, o padre Manuel de Nobrega aportou no Brasil dando início à atuação dos jesuítas nas Américas; Desde sua chegada até sua expulsão, a atuação da Companhia foi intensa (HOLLER, 2013). 
É possivel pensar que, sendo a viola um instrumento popular e de fácil transporte, estaria disponivel também à mão dos portugueses que vieram ao Brasil para povoar a Colônia. Em consulta a documentação de inventários, Ernani da Silva Bruno (200 l) relata a presença de violas nas mãos de leigos, ou seja, não eclesiásticos no Brasil. A presença marcante da viola na região da Paulistânia (Atualmente São Paulo, Norte do Paraná, Coiás, Mato Grosso do Sul, Mato Grosso, Sul do Tocantins e Triangulo Mineiro) demonstra o quanto o instrumento adentrou as terras brasileiras através da ação dos bandeirantes.

Durante o período colonial, o fluxo migratório de portugueses chegando ao Brasil, legal ou clandestinamente, é um estudo complexo da trama social. Embates, hostilidade, retorno, fixação, podem ser adicionados a isso. Em 1709, Portugal passa a exigir a necessidade de emissão de passaporte aqueles que desejassem se fixar na colônia (TABORDA, 2016). Os pequenos núcleos urbanos, necessitados de pequenos comércios, sobressaem como um destino comum aos recémchegados. Esse processo migratório trouxe consigo mestres violeiros que cruzaram o Atlântico na tentativa de alcançar novos rumos no Brasil, uma terra de esperança e paz.

Domingos Ferreira, um construtor de violas que residiu em Vila Rica, endossa o número de emigrantes. $\bigcirc$ seu inventário descreve detalhadamente todos os itens de sua oficina. Segundo Castagna (2013), Domingos Ferreira não era clérigo. Até o momento, o violeiro não aparece relacionado nas listas de pagamentos de músicos, tampouco como copista. Pode-se imaginar que não tenha se relacionado musicalmente com os músicos do repertório sacro. Ao que parece, teria atuado apenas na construção de violas?

$\bigcirc$ inventário aponta dados sobre os principais fornecedores de material do construtor e os respectivos valores cobrados. Nele, encontramos o preço dos seguintes materiais: maços de cordas de tripa importadas, madeiras para construção do instrumento fornecida por vendedores locais, tampos importados de Veneza, suas ferramentas e moldes para a construção dos instrumentos, as violas de diferentes tamanhos produzidas em seu ateliê com seus respectivos preços de comercialização, e outros bens pessoais de sua casa-oficina. 
Conforme o próprio inventário pode sugerir o violeiro não produzia todas as partes do instrumento, já que importava algumas partes da Europa, como o tampo vindo de Veneza. A razão para se utilizar madeira diferente já era conhecida e é mencionada por Antônio da Silva Leite (1796) ao tratar da construção de instrumentos:

\begin{abstract}
a madeira da sua construção deve ser de plátano muito seca, isto se entende não o tampo, porque este deve ser de Veneza, por ser madeira mais leve; e sendo ela de veia fina e rija, muito melhor, porque o som das cordas reflete mais, e faz um excelente efeito, estando o bojo ou cabaço bem coligado, e de tal sorte unido que nele não haja buraco por onde the entre o ar. (s.p)
\end{abstract}

Domingos Ferreira produzia em sua oficina quatro tipos de instrumentos: a viola grande, a meia viola, o descante e o machinho. Esses instrumentos eram comercializados com valores diferentes, sendo o primeiro o mais caro e o último mais barato. Na comparação feita por Castagna a outros inventários observa-se que os instrumentos confeccionados na Europa tinham preços menores se comparados aos produzidos e vendidos aqui no Brasil.

A presença de Domingos Ferreira abre novas indagações sobre a vida musical colonial mineira, abrindo a margem a vislumbrar a execução de um repertório de música profana neste espaço.

A Vila de Queluz (atual Conselheiro Lafaiete), pertencente à Comarca de Ouro Preto, em Minas Gerais, também apresenta construtores do instrumento. A produção local de violas apresenta uma característica quanto a confecção do instrumento. Ele era composto por cordas duplas e triplas que totalizavam 12 cordas a semelhança da viola Toeira de Coimbra. Levando em conta o fluxo migratório, teriam esses construtores naturalidade em Coimbra dado a particularidade identitária do instrumento? Abaixo segue uma tabela com o nome de alguns violeiros da Vila de Queluz. 
Violeiros em Queluz, Minas Cerais (1831)

\begin{tabular}{|l|l|l|l|}
\hline Nome & Idade & Condição & Escravos \\
\hline Leonardo José Vieira & 34 & Branco, casado & 1 \\
\hline Joaquim Rodrigues Vieira & 14 & $\begin{array}{l}\text { Branco, solteiro, } \\
\text { filho de lavrador }\end{array}$ & 2 \\
\hline Theodorio Álvares Ferreira & 26 & Branco, casado & 2 \\
\hline Feliciano José Barbosa & 34 & Branco, casado & 8 \\
\hline Januário José Barbosa & 32 & Branco, casado & 4 \\
\hline Antônio Rodrigues Pereira & 33 & Branco, solteiro & 3 \\
\hline João José Peixoto & 30 & Branco, casado & 2 \\
\hline
\end{tabular}

Tabela 1

As medidas e características do instrumento de Queluz são muito semelhantes à da viola Toeira. Como parte de seu acervo, a musicóloga Anna Maria Kiefer possui uma viola adquirida em um antiquário na cidade de São João Del-Rei, em Minas Gerais cujas características muito se assemelham.

A difusão da viola no território brasileiro teve não apenas a contribuição dos jesuítas, dos bandeirantes, mas conta também com a presença dos construtores nos núcleos urbanos. A partir das iconografias produzidas ao longo do século XIX pelos estrangeiros que vieram ao Brasil podemos visualizar uma pequena parte desse alcance. Gravuras como Festa da Rainha, Em Minas (Figura 2) de Martius e Spix, em Viagem pelo Brasil (1817-1821). Costumes de São Paulo, Prancha II, 17 de J. M. Rugendas (figura 3). Folia do Divino do Imperador do Espírito Santo de Jean-Baptiste Debret, 1839 (figura 4); Festa do divino Espirito Santo de Henry Chamberlain (Figura 5); são exemplos disso. 


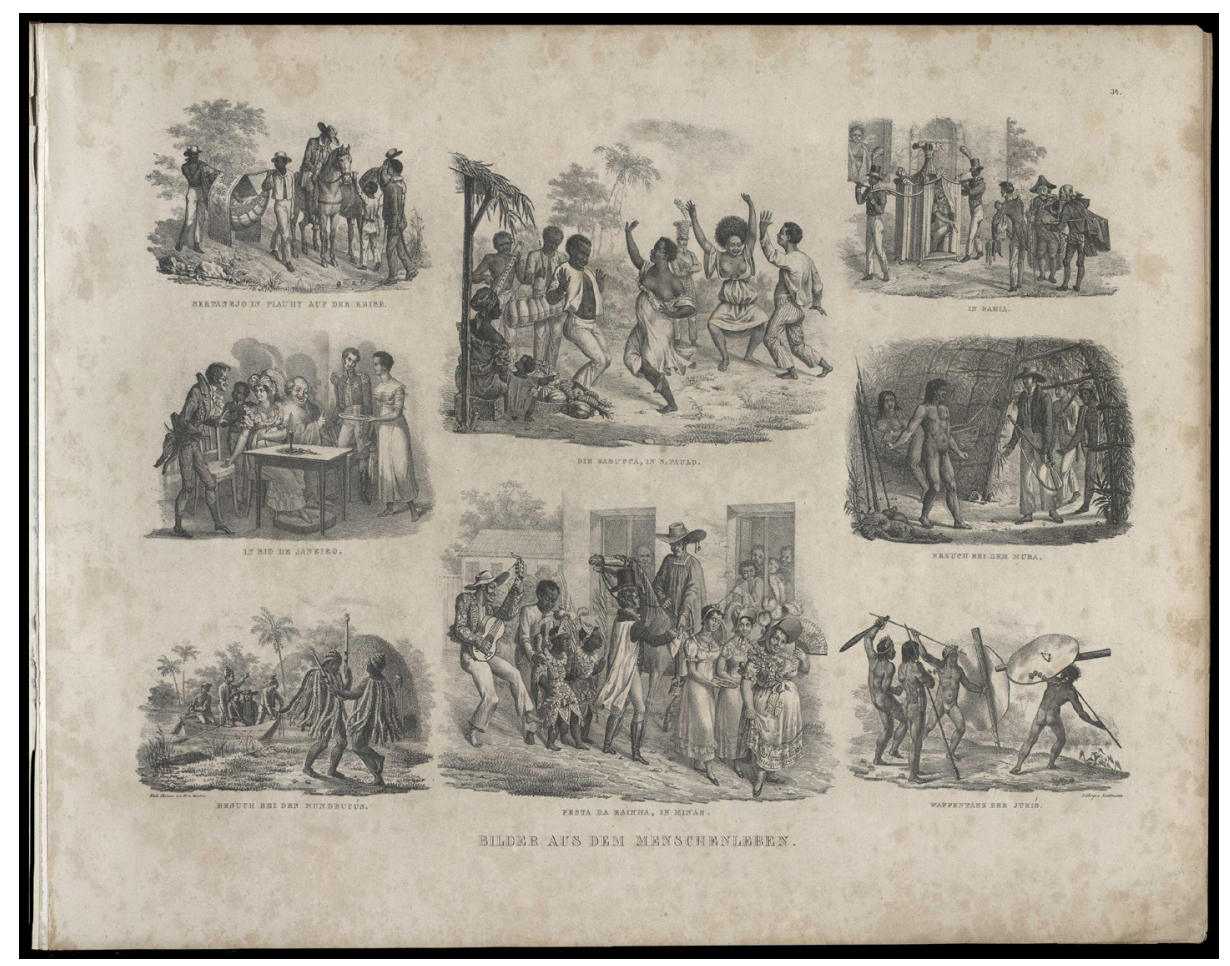

Figura 2 Festa da Rainha, in Minas. Martius e Spix. 


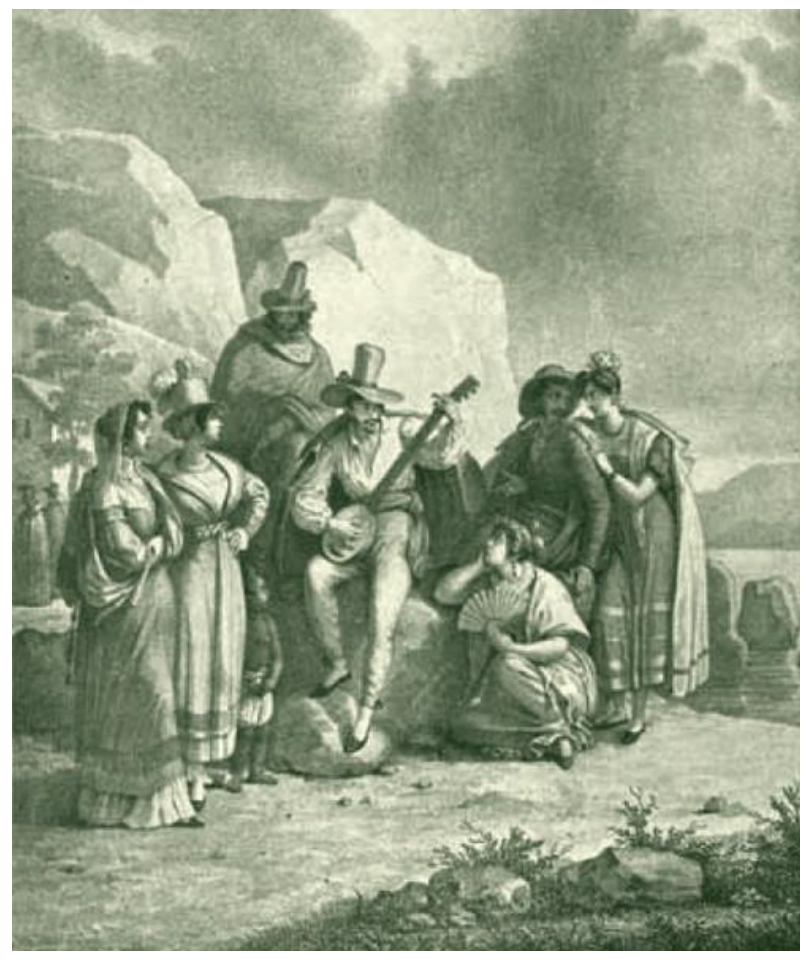

Figura 3 - Costumes de São Paulo. J. M. Rugendas.

A cidade de São Sebastião do Rio de Janeiro, capital do Brasil durante o período colonial, naturalmente, desfrutou dos sons sociais produzidos pelo instrumento em suas ruas, casas e salões. Segundo Taborda "a popularidade da viola no Rio de Janeiro em fins do século XVIII pode ser atestada pelo estabelecimento de fabricantes do instrumento no centro da cidade, dando, inclusive, nome ao logradouro que os acolheu: a Rua das Violas" (2011, p. 53). 


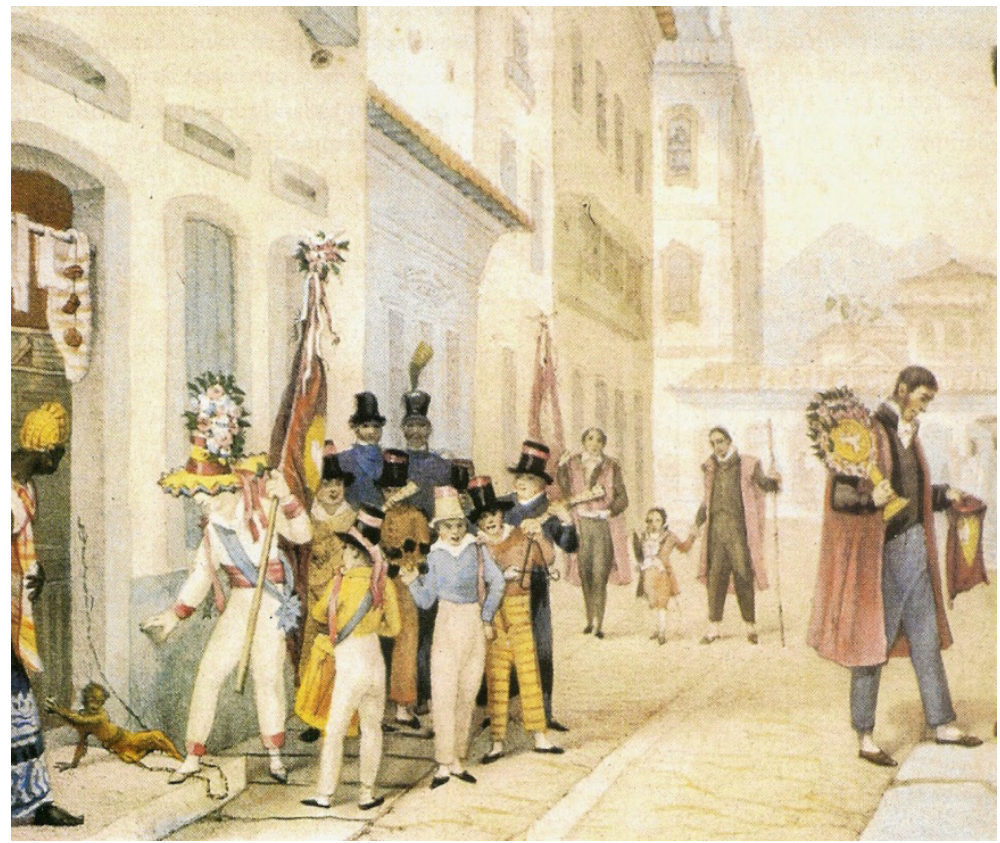

Figura 4 - Folia do Divino do Imperador do Espírito Santo, 1839. Jean-Baptiste Debret.

almanaque da cidade do Rio de Janeiro 1792/1794 apresenta uma lista de violeiros ${ }^{9}$ estabelecidos à Rua das Violas. A rua que abrigou esses construtores "conservou seu nome até 1869, quando a Câmara Municipal the deu a designação, que ainda hoje se mantem, de Rua Teófilo Otoni" (TABORDA, 2011, p. 53)

9 Violeiros citados no Almanaque da cidade do Rio de Janeiro: Antônio José Tavares, Jose Correia de Paiva, João Francisco Viana, José Dias de Castro Guimarães e Manoel Gonçalves Toledo. 


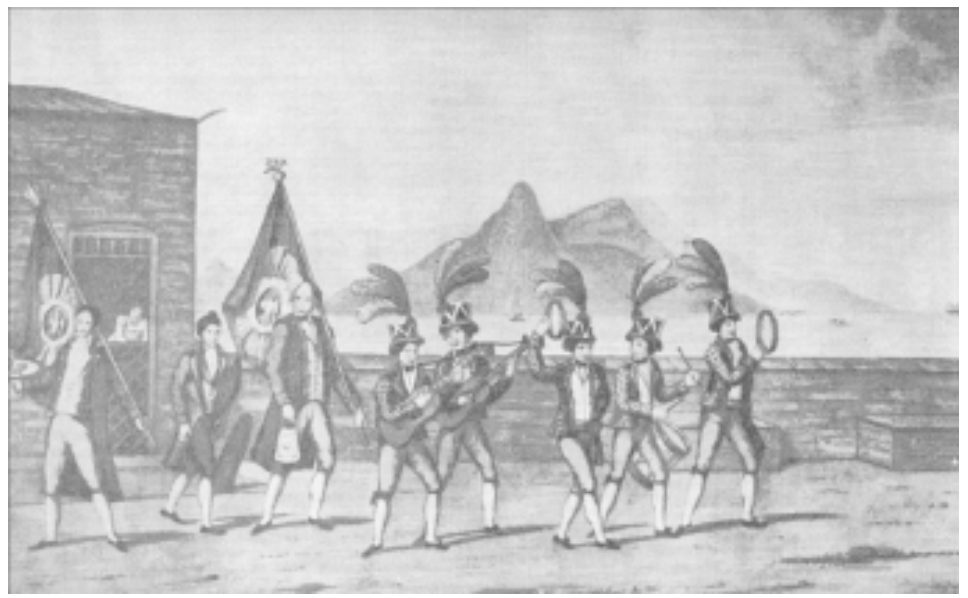

Figura 5 - Folia do Divino Espirito Santo. Henry Chamberlain.

Taborda $^{10}$ (2016) aponta um fluxo migratório feito por violeiros portugueses com destino ao Brasil a partir do século XIX. Alguns deles estabeleceram suas oficinas no centro do Rio de Janeiro e reproduziram o modelo de funcionamento português "na qual os mestres trabalhavam e coordenavam a atividade de um ou dois oficiais, de um ou dois aprendizes entre os quais provavelmente os filhos que the iriam suceder" (2016, p. 294).

Almanak Laemmert (1844-1889), uma importante fonte sobre as atividades comerciais desenvolvidas na cidade do Rio do Janeiro, revelam as únicas referências a respeito da atividade dos violeiros na cidade. Segundo Taborda, as primeiras publicações sobre a construção de instrumentos de cordas dedilhadas na cidade datam de 1845 quando "António Machado Lourenço, José Alves de Carvalho e Manuel José de Lima fornecem os endereços de suas oficinas" (2016, p.294).

10 "A consulta a fontes documentais de acervos no Brasil e em Portugal possibilitou realizar um levantamento de 46 nomes de artesãos portugueses estabelecidos no Rio de Janeiro ao longo do século XIX, dos quais de apenas 14 conseguimos dados mais precisos tais como a proveniência, traços físicos, idade e data de chegada. Alguns desses fabricantes foram responsáveis pelo estabelecimento das lojas de música que se tornariam desde meados do século XIX, ponto de encontro e referência para a atividade de músicos cariocas". 
Construtores de instrumentos de cordas dedilhadas no Almanak Laemert (1845-1890)

\begin{tabular}{|c|c|}
\hline Ano & Número de construtores \\
\hline 1845 & 3 \\
\hline 1850 & 4 \\
\hline 1852 & 4 \\
\hline 1853 & 3 \\
\hline 1854 & 5 \\
\hline 1860 & 6 \\
\hline 1870 & 7 \\
\hline 1880 & 7 \\
\hline 1890 & 5 \\
\hline
\end{tabular}

Tabela 2

prestígio que a valorizava cedeu espaço à depreciação sócio histórica advinda pelos projetos de modernidade e progresso nos centros urbanos nas últimas décadas do século XIX. As práticas socioculturais que transitavam simultaneamente nos espaços urbanos e rurais passam a ser reprimidas para o funcionamento de uma nova engrenagem social: a vida nas metrópoles.

As cidades brasileiras do século XX, ainda por força do modelo de ocupação do solo durante o período colonial, muitas vezes conservavam em seu perímetro urbano características rurais (TINHORÃO, 20 10). Segundo Vilela (2013), o crescimento acelerado de nossas cidades não conseguiu parear o progresso com nossas tradições. Logo, as tradições remetiam-se ao atraso. Dessa forma, restou ao homem comum (caipira) reciclar e reutilizar algumas expressões artísticas consideradas "lixo cultural urbano". Ao recria-las, foram reintegradas à cultura pelas mãos do "caipira". Segundo Varoni (2007), a viola foi gradativamente tornando-se um instrumento de uso corrente as classes menos favorecidas, enquanto o piano passa a ocupar as casas mais abastadas e o violão os espaços urbanos. 


\section{Considerações finais}

Cruzou o Atlântico. Apreciada em Portugal e no Brasil; presente nas cortes, nos meios urbanos e rurais; por nobres e homens comuns; por brancos, índios, mulatos e negros; por nativos e estrangeiros. Diferentes formas, vários construtores. Sonoridades mágicas que destrancavam portas, janelas e fechaduras. Causou problemas, motivou aventuras, mas também alegrou. Proporcionou entretenimento social para alegrar, mas também para expressar a tristeza da alma, a saudade e o amor distante. Violas, o seu apreço proporcionou histórias.

Enraizada em nossa cultura lusófona. Sua praticidade, o fácil transporte e manuseio a conduziram pela vastidão territorial. Na historiografia é vista no acompanhamento de canções - Modinhas e Lundus - tanto no espaço urbano, como rural em manifestações populares. É curioso observar como ela não se apropriou de teatros e salas de concertos em sua história portuguesa e brasileira. Teria a viola, se privado do enclausurar das quatro paredes e se reservado a viver a liberdade aventureira do espírito juvenil e colono além-mar?

instrumento, em sua vertente brasileira, ainda carece de sistematizações metodológicas para o ensino. Mesmo com as recentes publicações, o segredo do violeiro ainda permanece na oralidadel auralidade a procura de um discípulo escolhido e hábil para se tornar iniciado.

A presença e atuação dos violeiros nos núcleos urbanos coloniais ainda carecem de um profundo estudo que traga a tona a documentação sobre quem foram esses sujeitos e sua interação com o meio em que aturam.

Enquanto fenômeno social, o fluxo migratório de violeiros precisa ainda de reflexão em inventários, nas relações comerciais entre fornecedores, materiais utilizados, valores de venda e importação. Questões óbvias por se tratar de uma prática comercial. Entretanto, as relações sociais precisam ser mais bem exploradas quanto a sua proximidade com as práticas urbanas, festas do catolicismo popular, relações socioeconômicas, recepção e ensino da prática artesã e a transmissão musical.

\section{3}




\section{Referências}

ALMEIDA, Antônio Augusto Marques de. Saberes e práticas de ciência no Portugal dos Descobrimentos. In: TENGARINHA, José (Org.). História de Portugal. Bauru, São Paulo: EDUSC; São Paulo: UNESP, 2000.

BARATA, Maria do Rosário Themudo. Portugal e a Europa na Época Moderna. In: TENCARINHA, José (Org.). Historia de Portugal. Bauru, São Paulo: EDUSC; São Paulo: UNESP, 2000.

BRITO, Manuel Carlos de. Estudos de História da Música em Portugal, Lisboa: Imprensa Universitária Editorial Estampa, 1989.

CRANMER, David; e BRITO, Manuel Carlos de. Crônicas da vida musical portuguesa na primeira metade do século XIX, Coleção Arte e Artista, Imprensa Nacional-Casa da Moeda, 1989.

BUDASZ, Rogério. The Five-Course Guitar (Viola) In Portugal And Brazil In The Late Seventeenth And Early Eighteenth Centuries. 200 I. Tese de Doutorado - Faculty Of The Graduate School University Of Southern California, EUA.

CASTACNA, P; SOUZA, M. J. F de; PEREIRA, M. T. C; Domingos Ferreira: um violeiro português em Vila Rica. Colóquio Internacional as Músicas Luso-Brasileiras No Final do Antigo Regime: Repertórios, Práticas e Representações, Lisboa, 7 a 9 de junho de 2008. Lisboa: Fundação Calouste-Gulbenkian, 2013.

COSTA LOBO, A. de Souza Silva. História da sociedade em Portugal no século XV. Lisboa: Imprensa Nacional, 1904.

FACERLANDE, Marcelo. Manoel Joaquim, improvisador de modinhas. Revista Brasiliana n² 27, p. 1 1-24, 2008.

FERREIRA, Manuel. A viola de 2 corações. Portugal: Ponte Delgada, 1990. 
HOLLER, Marcos. Os jesuítas e a música no Brasil colonial. São Paulo: Editora Unicamp, 2010.

NOGUEIRA, Gisela Gomes Pupo. A viola con anima: uma construção simbólica. 2008. Tese de doutorado - USP, SP.

OLIVEIRA, Ernesto Veiga. Instrumentos Musicais Populares Portugueses. Centro de Estudos de Etnologia Peninsular e Centro de Estudos de Antropologia Cultural. Lisboa. Fundação Calouste Culbenkian, 1966.

RUAS, José Jarbas. Nova Arte de Viola: Contextualização Histórica e Análise Crítica de um Tratado Setecentista. 2013. Dissertação (Mestrado) - Universidade Federal do Rio de Janeiro, RJ.

TABORDA, Marcia. "Introdução do Violão no Rio de Janeiro". Revista Brasiliana nº 15. Setembro, 2003.

Brasileira, 2011.

Violão e identidade nacional. Rio de Janeiro: Civilização . "De Coimbra ao Rio de Janeiro: Os violeiros da familia Couceiro e sua participação nas exposições regionais e internacionais". Boletim do Arquivo da Universidade de Coimbra. v. 29, p.291-321, 2016.

TINHORÃO, José Ramos. História Social da Música Popular Brasileira. São Paulo: Editora 34, 2010.

VARONI DE CASTRO, Renato Moreira. Os caminhos da viola no Rio de Janeiro do século XIX. 2007. Dissertação (Mestrado) - Universidade Federal do Rio de Janeiro, RJ.

VILELA, Ivan. Cantando a própria história: música caipira e enraizamento. São Paulo: EDUSP, 2013 


\section{Sobre o autor}

José Jarbas Ruas é professor do Magistério Superior - UFT. É Mestre em Musicologia Histórica na linha de pesquisa História da Música brasileira e Ibero-Americana pela Universidade Federal do Rio de Janeiro (20 13). Possui bacharelado em Música com habilitação em violão pela UFRJ (2010). É professor do Magistério Superior pela Universidade Federal do Tocantins na Licenciatura em Educação do Campo: Artes Visuais e Música, campus Tocantinópolis.

Recebido em: $11 / 09 / 2016$ Aprovado em: 09/11/2016 